\title{
Theoretical study of the dissolution kinetics of galena and cerussite in an abandoned mining area (Zaida mine, Morocco)
}

\author{
LamiaeEl Alaoui, AbdelilahDekayir* \\ UR Geotech, Département de Géologie, Université Moulay Ismail, Meknès, Maroc
}

\begin{abstract}
In the abandoned mine in Zaida, the pit lakes filled with water constitute significant water reserves. In these lakes, the waters are permanently in contact with ore deposit (cerussite and galena). The modelling of the interaction of waters with this mineralization shows that cerussite dissolves more rapidly than galena. This dissolution is controlled by the $\mathrm{pH}$ and dissolved oxygen concentration in solution. The lead concentrations recorded in these lakes come largely from the dissolution of cerussite.
\end{abstract}

\section{Introduction}

In the worldwide, abandoned mine sites are known by significant degradation of water quality and contamination of aquatic systems by heavy metals, which are known to be very harmful to human health due to the acid mine drainage phenomena causes by the oxidation of the sulphides, in particular pyrite and arsenopyrite. The oxidation of the sulphides causes a significant decrease in the $\mathrm{pH}$, which causes the dissolution of the mineral phases and the release of metals in solution.

In the upper Moulouya, water is a rare commodity. In fact, the aridity of the climate and the low rate of precipitation require the preservation of lakes waters which represent important reservoirs for the irrigation of the crops and the watering of the livestock.

In the Zaida mine, primary mineralization consists mainly of cerussite $(70 \%)$ and galena [7]. In the absence of sulphides such as pyrite and the presence of a granitic geological environment, the $\mathrm{pH}$ of surface-flowing water is often alkaline.

In the pit lakes, water is in permanent contact with the remains of galena and cerussite. In fact, the concentrations of lead and arsenic found in these waters are controlled by chemical reactions between the mineralization and the aqueous solution. This work deals with the theoretical study of the dissolution kinetics of galena and cerussite considered as the main mineral phases source of heavy metals. This study was conducted using the PHREEQC modelling program.

\footnotetext{
${ }^{*}$ Corresponding author: dekayir@yahoo.frTel: $(+212668105079)$
} 


\section{Studied site}

The abandoned Zaida mine is located in the centre of the upper Moulouya watershed, at $26 \mathrm{~km}$ north of Midelt. The mining activity was done from 1972 to 1985 . The main ore extracted is lead, mainly carried by cerussite $(70 \%)$ and galena [7]. The climate in this locality is arid to semi-arid with rainfall of $300 \mathrm{~mm} /$ year and mean annual temperatures ranging from $18^{\circ} \mathrm{C}$ to $29^{\circ} \mathrm{C}$, while minimum winter temperatures are in the range of 14 to $21^{\circ} \mathrm{C}[2]$

The studied lake ZA located near the tailing I (mining waste), is filled with surface water with an area of about $50 \mathrm{Ha}$ accumulating a volume of water of about $1 \mathrm{Mm}^{3}$; its chemical composition sometimes shows concentrations of metals in lead and Arsenic [1, 3]

Table1.Characteristic of the lake

\begin{tabular}{|c|c|}
\hline Perimeter & $1,36 \mathrm{Km}$ \\
\hline Area & $50 \mathrm{Ha}$ \\
\hline Depth & $5 \mathrm{à} 12 \mathrm{~m}$ \\
\hline $\begin{array}{c}\text { Volume of } \\
\text { water }\end{array}$ & $1 \mathrm{Mm} 3$ \\
\hline
\end{tabular}

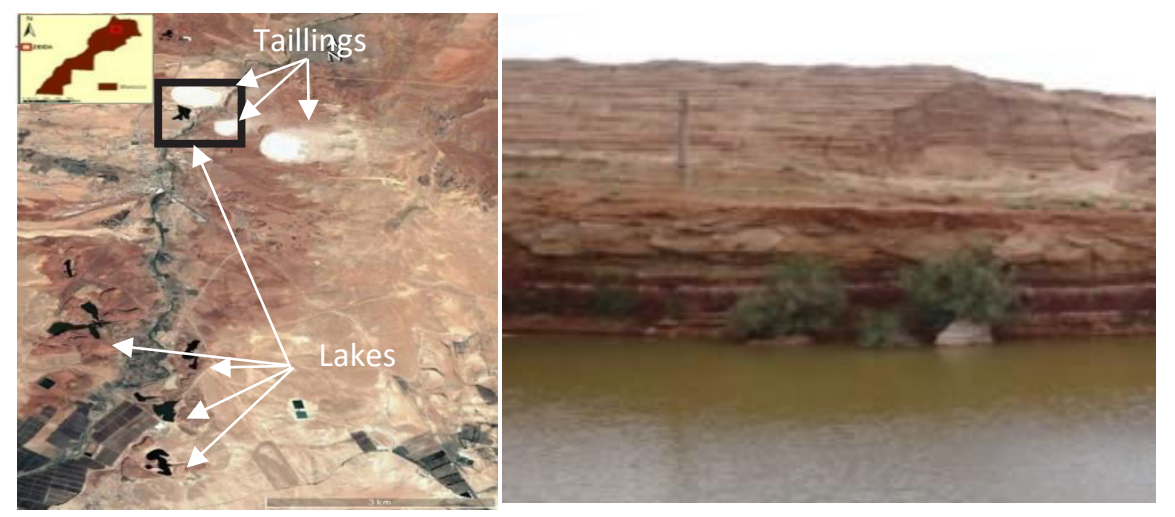

Fig.1. mining area of Zaida and location of the lake ZA.

\section{Material and methods}

\subsection{Collect and analysis of ZA lake waters}

The main physical-chemical parameters (temperature, $\mathrm{pH}$, redox potential, dissolve dioxygen concentration, conductivity) of the water were studied in situ using a portable multiparameter of the HQ40d type. The samples taken were filtered at $0.2 \mu \mathrm{m}$ and stored in Teflon bottles. Water samples for cations chemical analysis were acidified by the addition of nitricacid HNO3. The other samples were prepared for anion analysis. These samples were analyzed by ICS-MS in the Hydrosciences Montpellier laboratory (France).

\subsection{Mineralogical analyzes}

In Zeida, a sample of arkose ore deposit was crushed with an agate mortar and was analyzed by X-ray diffraction (XRD) in the Research Center at Meknes university. The 
used device is a Shimadzu type diffractometer. The mineralogical analysis allowed calculating the proportions of the mineral phases contained in the arkose.

\section{Results}

\subsection{Mineralogical analysis of mineralized arkose}

Mineralogical analysis by X-ray diffraction of mineralized arkose shows the presence of typical minerals of a granitic heritage such as quartz, orthoclase, muscovite with galena and cerussite (Table 2).

Table 2. Mineralogical composition of the analyzed arkose in mole and in percentage

\begin{tabular}{|c|c|c|c|c|c|c|c|}
\hline Elements & Galena & Muscovite & Kaolinite & Cerussite & Quartz & Orthoclase & Baryte \\
\hline Composition & 0,19 & 0,07 & 0,08 & 0,16 & 0,17 & 0,17 & 0,17 \\
\hline$\%$ & 18,81 & 6,93 & 7,92 & 15,84 & 16,83 & 16,83 & 16,83 \\
\hline
\end{tabular}

\subsection{Physical-chemical analysis of the lake ZA waters and calculation of chemical speciation}

To examine the degree of contamination of Lake ZA by heavy metals and arsenic, a field survey was conducted in this area in October 2010 (dry season), to sample the surface pit lake waters of the ZA to determine the concentrations of trace elements and arsenic. An example of these analyzes is given in Table 3.

Table3. Chemical analysis of ZA lake waters

\begin{tabular}{|c|c|c|c|c|c|c|c|c|c|}
\hline \multicolumn{7}{|c|}{ Physicochemical parameters } & \multicolumn{3}{|c|}{ Total alkalinity(ppm) } \\
\hline $\begin{array}{l}\text { Conductivity } \\
(\mu \mathrm{S} / \mathrm{cm})\end{array}$ & \multicolumn{2}{|c|}{$\begin{array}{c}\text { Temperature } \\
\left({ }^{\circ} \mathrm{C}\right)\end{array}$} & $\mathrm{pH}$ & $\begin{array}{l}\text { ORP } \\
(\mathrm{mV})\end{array}$ & pe & $\begin{array}{c}\text { Dissolve } \\
\text { doxygen } \\
\text { (ppm) }\end{array}$ & {$\left[\mathrm{CO}_{3}{ }^{2-}\right]$} & [TAC] & {$\left[\mathrm{HCO}^{3-}\right]$} \\
\hline 5630 & \multicolumn{2}{|c|}{15.6} & 9.02 & 21 & 0.35 & $8.32 / 104 \%$ & 82.82 & 616.30 & 450.7 \\
\hline \multicolumn{10}{|c|}{ Concentration in traced elements (ppb) } \\
\hline $\mathrm{Li}$ & B & $\mathrm{Al}$ & $\mathrm{Ca}$ & $\mathrm{V}$ & Cs & $\mathrm{Mn}$ & $\mathrm{Fe}$ & Co & $\mathrm{Cu}$ \\
\hline 1851 & 55.95 & 11.09 & 29000 & 5.92 & 0.219 & 25.2 & 3.621 & 0.584 & 1.844 \\
\hline $\mathrm{Zn}$ & As & $\mathrm{Rb}$ & $\mathrm{Sr}$ & Mo & $\mathrm{Sn}$ & $\mathrm{Sb}$ & $\mathrm{Ba}$ & $\mathrm{Pb}$ & $\mathrm{U}$ \\
\hline 29.61 & 43.89 & 25.78 & 2823 & 18.88 & 0.018 & 1.867 & 64.37 & 0.022 & 0.022 \\
\hline
\end{tabular}

These hydrogeochemical analyses of the samples were simulated using the PHREEQC numerical code (version 3.3.12) [5], to evaluate the chemical speciation of the dissolved constituents and calculate the saturation of different mineral phases. The thermodynamic database wateq4f.dat has been used for chemical equilibrium calculations. The results of calculation of the speciation of lead and arsenic showed that in the case of lead, the bulk of the metal in solution is in $\mathrm{PbOH}^{+}$form, whereas arsenic exists in its form $\mathrm{HAsO}_{4}{ }^{-2}$ at 57 , $37 \%$, Zinc in its $\mathrm{Zn}(\mathrm{OH})_{2}$ form (39.76\%) and copper in $\mathrm{Cu}(\mathrm{OH})_{2}$ form (2.85\%) (Fig. 2) 
Table 4.Chemical speciation of lead, zinc and arsenic

\begin{tabular}{|c|c|c|c|c|c|}
\cline { 2 - 6 } \multicolumn{1}{c|}{} & & $\mathrm{Pb}$ & $\mathrm{Zn}$ & $\mathrm{As}$ & $\mathrm{Cu}$ \\
\hline \multirow{3}{*}{ Lake ZA } & Molality & $7,32 * 10^{-11}$ & $4 * 10^{-7}$ & $5,77 * 10^{-7}$ & $2,87 * 10^{-8}$ \\
\cline { 2 - 6 } & $\%$ & $0,0073 \%$ & $39,76 \%$ & $57,37 \%$ & $2,85 \%$ \\
\cline { 2 - 6 } & Elements & $\mathrm{PbOH}^{+}$ & $\mathrm{Zn}(\mathrm{OH})_{2}$ & $\mathrm{HAsO}_{4}^{-2}$ & $\mathrm{Cu}(\mathrm{OH})_{2}$ \\
\hline
\end{tabular}

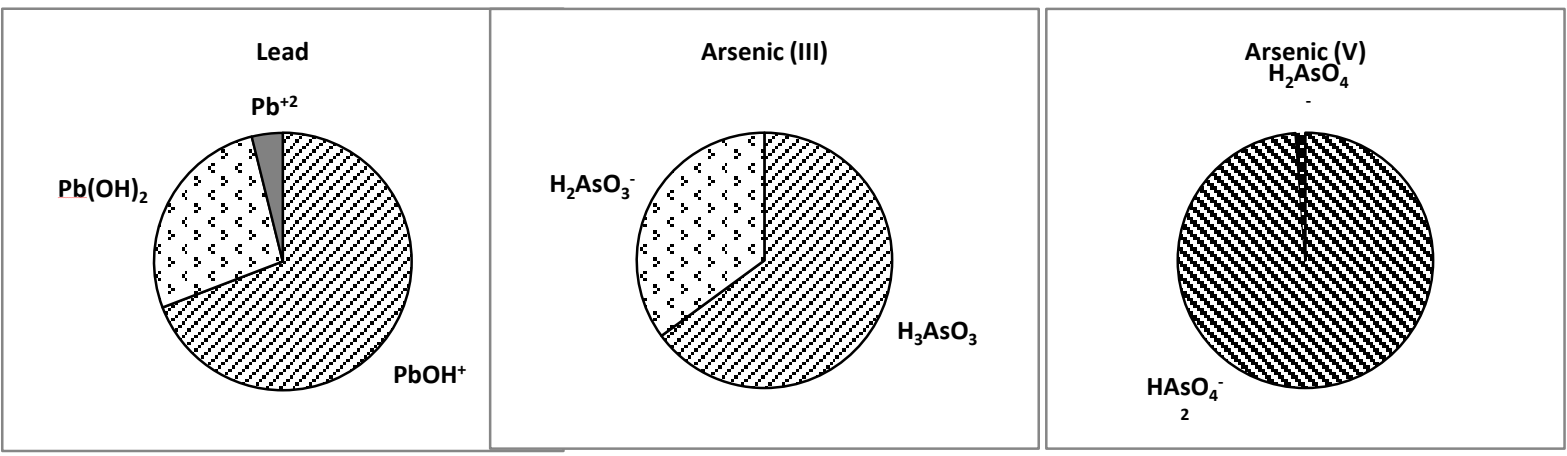

Fig. 2. Chemical speciation of lead and arsenic in the lake ZA

The calculation of the saturation indices shows that the waters of Lake ZA are undersaturated for most compounds of Lead, Zinc and Arsenic, but supersaturated in Iron with a possible precipitation of ironoxides such as hematite. In the case of lead, the compound $\mathrm{Pb}$ $(\mathrm{OH})_{2}$ is in equilibrium with the aqueous solution.

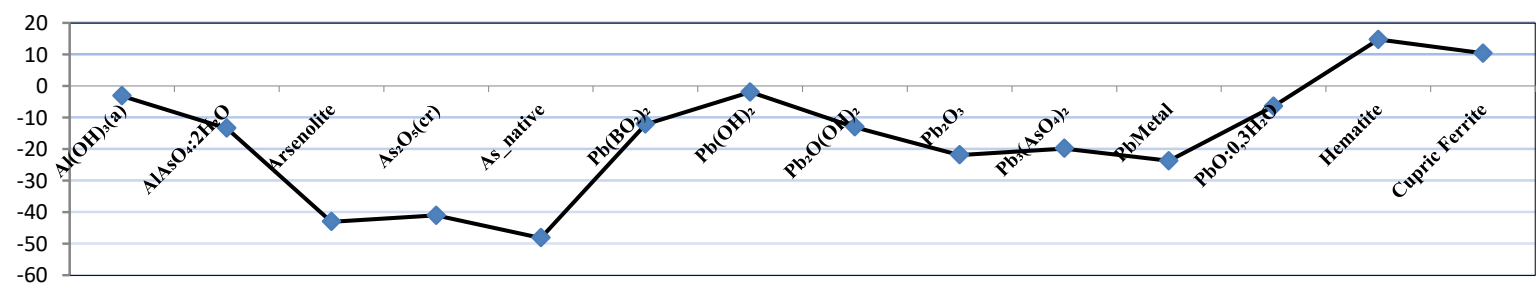

Fig. 3. Water saturation indices of Lake ZA

\subsection{Simulation of the dissolution reactions of galena and cerussite}

The dissolution of galena has been the subject of several works [6], Indeed, its dissolution rate can be quantified by the following equation:

$$
\begin{gathered}
P b S+2 H^{+}=P b^{2+}+H_{2} \operatorname{Saq}[8] \\
R=\frac{V}{S} \cdot \frac{d C_{P b}}{d t}=k \cdot[H+]^{n} \text { et } \log R=\log k-n p H[8]
\end{gathered}
$$


$R$ : dissolution rate $\left(\right.$ mol/l/s) $; t$ : reaction time elapsed $(s) ; S:$ surface area of galena $\left(m^{2}\right) ; C_{P b}$ : concentration of lead; $V:$ volume of solution $(l) ; k:$ dissolution rate constant $;\left[H^{+}\right]:$activity of $H^{+} ; n$ : Reaction order

While the dissolution of cerussite has been little discussed.

$$
\mathrm{PbCO}_{3}+2 \mathrm{H}^{+}=\mathrm{Pb}^{2+}+\mathrm{CO}_{2}+\mathrm{H}_{2} \mathrm{O}[5]
$$

To understand the interaction of Lake ZA waters with mineralized arkoses, the dissolution rates of galena and cerussite were simulated at $\mathrm{pH}=9$ over a 31 years period corresponding to the mine abandonment period. The alteration solutions used in the simulation correspond to rainwater and water from the lake ZA.

The obtained results in both cases show that the dissolution rate of galena remains much lower than that of cerussite (Fig. 4). Consequently, very low concentrations of $\mathrm{Pb}^{2+}$ in solution obtained in both cases are similar and of the order of $10^{-13} \mathrm{~mol} / 1$, which corresponds exactly to the concentration of dissolved lead measured in the same lake $\left(1,06^{*} 10^{-13} \mathrm{~mol} / 1\right)$. In summary, the lead concentration is essentially related to the dissolution of cerussite (Fig. 4). It is important to note that the waters of the lake ZA have very low electron potential values (pe), resulting in stagnant and less oxygenated water, which slows down the dissolution rate of metal phases.

\section{Conclusion}

In the abandoned mine of Zaida, the pit lakes store significant amounts of water used by local residents for crop irrigation and livestock watering. The waters of these lakes are permanently in contact with the mineralized arkose in cerussite and galena which, by dissolution, release metals in solution, especially lead and arsenic.

The dissolution models of galena and cerussite elaborated by PHREEQC show that the dissolution of these minerals is essentially controlled by the $\mathrm{pH}$ and oxygen in solution. Calculations show that cerussite dissolves more rapidly than galena inducing an increase in the $\mathrm{pH}$ of these waters. The lead concentrations recorded in these waters are largely controlled by the dissolution of cerussite. 


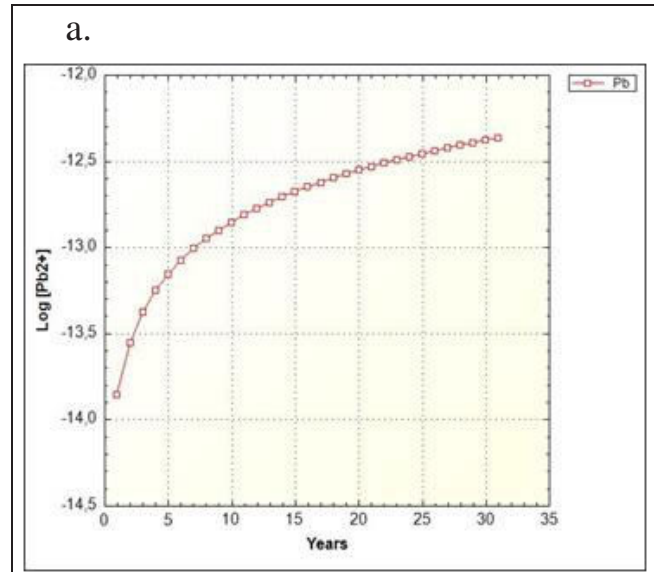

b.
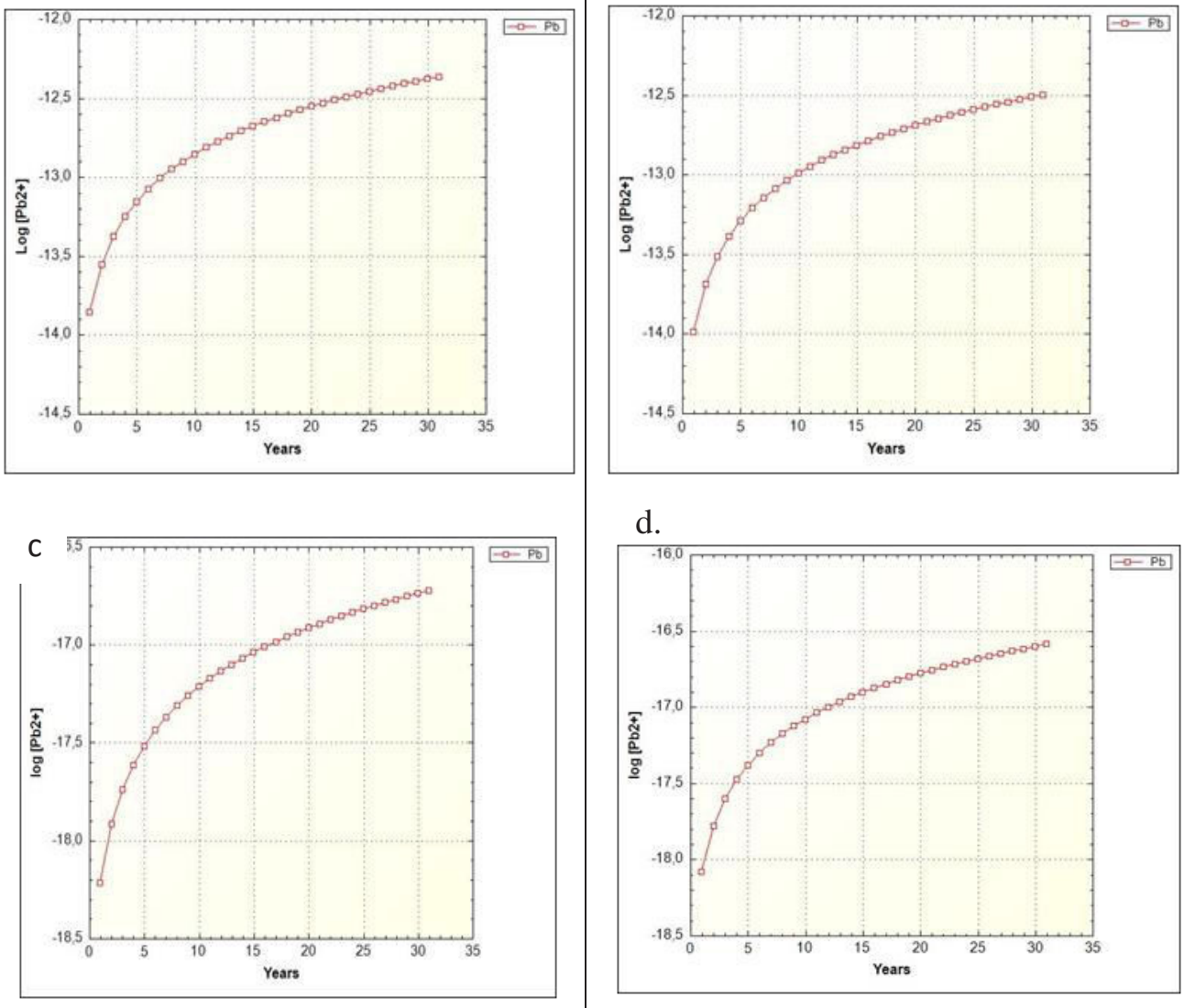

d.

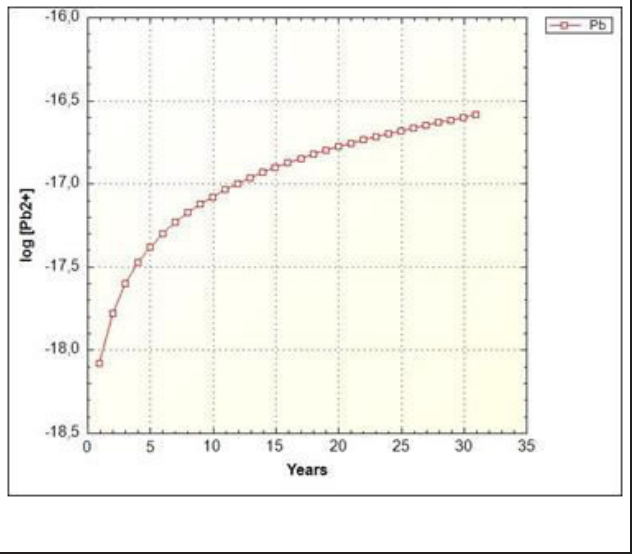

Fig. 4. Concentrations of $\mathrm{Pb}^{2+}$ in aqueous solutions calculated at $\mathrm{pH}=9$ for 31 years, in the case of the dissolution of cerussite with (a: rainwater, b: lake water) and Galena with (c: rainwater, d: lake water)

This work have been granted by CNRST under the project priorities No 34/2015

\section{References}

1. E.M. Benyassine, A. Dekayir, C. Casiot,. I.J.E.R.T. 11 (2013)

2. M.Combe ,M. Simonot Notes \& M. Serv.Geol. Maroc, $\mathbf{N}^{\circ}$ 231(1971)

3. M.L. ElHachimi, L. ElFounti, A. Bouabdli, N. Saïdi, M. Fekhoui, N. Tassé, R.S.E. 20, (2007)

4. R. Nasanen, P. Merilainen, K. Leppanen, ActaChim. Sinica.15, (1961)

5. D.Parkhurst, C.Appelo, USGS, (1999).

6. A. Salih, Murat, Erdemoglu, U.Gökhan, A.Ali, Hydrometallurgy. 88,(2007)

7. J. M. Schmitt Thèse de Doctorat. ENSM, (1976), Paris

8. Z. Sheng, L. Jianping, W. Yurong, H. Guangqian, Ap. Geochem, 19 (2004) 